\title{
LJUDMILA BOKAL
}

\section{STROKA KOT TERMINOGRAFSKO IZHODIŠČE (OB PRIMERU KLEKLJARSKE TERMINOLOGIJE)}

CoBISS: 1.01

\begin{abstract}
Prispevek opisuje sinhrona in diahrona merila, po katerih je mogoče opredeljevati stroke, ki imajo uslovarjeno svoje izrazje v slovarjih. Navezuje jih na klekljarstvo, ki ima svoje izrazje kodificirano v strokovnem slovarju in ki je ena od antropoloških strok, ki pridobiva strokovno vrednost kot terminologizirana veda.

Ključne besede: terminologija, terminografija, terminološki slovar, stroka, klekljarstvo
\end{abstract}

\section{A Profession as a Terminographic Point of Departure (Lace-Making Terminology)}

This article describes the synchronic and diachronic criteria by which it is possible to define professions whose terminology has been codified in dictionaries. It examines lace-making, whose terminology is codified in a technical dictionary and which is a profession that has been studied anthropologically and has received increasing professional terminological attention.

Keywords: terminology, terminography, terminological dictionary, profession, lace-making

1 Kljub temu da jezik kot sredstvo sporazumevanja celovito odraža stvarnost in tako tudi pojme določene stroke, ki v stvarnosti prepleteno živijo, je avtonomnost posameznih strokovnih področij tako velika, da se odraža na več jezikovnih ravninah, najmočneje v izrazju. V jezikoslovni literaturi je večkrat omenjena trditev, ${ }^{1}$ ki se

1 Toporišičeva slovnica šteje izrazje med konstitutivna znamenja strokovnih jezikov; med njimi Toporišič najprej omenja praktičnostrokovnega: »Ena vrsta strokovnega jezika je praktičnostrokovni jezik. Podoben je praktičnosporazumevalnemu, le da je v njem precej več strokovnega izrazja. [...] Značilne zanj so poleg tipičnega izrazja še tipične ustaljene besedne zveze, rekla in kalki.« (Toporišič 2000: 29) Strokovno izrazje zaznamuje tudi znanstveni jezik: »Najvišja vrsta strokovnega jezika je t. i. znanstveni jezik. S praktičnostrokovnim jezikom ga povezuje strokovno izrazje, vendar je znanstveno obširnejše.« (Toporišič 2000: 29) Toporišič z izrazjem opredeljuje tudi navadni strokovni (poljudnoznanstveni) jezik: »V takih [poljudnoznanstvenih - op. L. B.] besedilih se pisci trudijo tudi zapletene stvari povedati čim bolj preprosto in jasno, namesto s tujo besedo (in tudi $\mathrm{z}$ izrazjem) raje z domačo« (Toporišič 2000: 29). Tudi novejša jezikoslovna literatura daje izrazju relevantno mesto: »Jezikovna komunikacija opravlja številne sporočevalne naloge in največkrat gre pri tem za poročanje o določeni temi ali področju. Tako rekoč vsaka tema v komunikaciji pomeni, da bomo pri govorjenju ali pisanju o njej uporabili izraze, povezane s temo. Če je tema ozko specializirana, bomo v komunikaciji uporabili specializirano izrazje.« (Vintar 2008: 13) Specializirano izrazje je konkretizirano z izrazom termini: »Funkcijskozvrstna teorija $\mathrm{v}$ osnovi zadovoljivo pojasni, kako in koliko se jezik stroke razlikuje od splošnega jezika. Največja razlika med splošnim in strokovnim jezikom je v izbiri besedišča in deležu terminov.« (Jemec Tomazin 2010: 138) 
navezuje na pojem strokovni jeziki. Vsaka terminologija oziroma terminološka leksi$\mathrm{ka}^{2}$ je potemtakem odsev predmeta svoje obdelave. Namen pričujočega sestavka je raziskati merila metajezika, ki pridejo v poštev za opredelitev avtonomnosti določenega strokovnega področja s terminografskega stališča. Ponazorjena bodo ob primeru klekljarske terminološke leksike, ki je leta 2013 dobila registracijo svojega izrazja v Malem klekljarskem izrazju iz žirovskih del Tončke Stanonik (MKS, izdajatelj Inštitut za slovenski jezik Frana Ramovša ZRC SAZU, soizdajatelj Klekljarsko društvo Polhov Gradec) avtorice Ljudmile Bokal. Ob kodifikaciji (uslovarjenju) izrazja določene stroke, ki spada med obrobne antropološke, se pojavi vprašanje, katere so njene strokovno določene posebnosti, ki opredeljujejo stroko in botrujejo odločitvi o terminografski obdelavi. Obenem se članek dotika tudi razmisleka, ali poleg izrazja, ki najbolj relevantno dokazuje specifičnost določene stroke in se izkazuje na pomenski jezikovni ravnini, prispeva k avtonomnosti stroke še katera od jezikovnih ravnin.

1.1 Ob izhodiščni trditvi, da je izrazje tisto, ki najbolj prepoznavno določa specifičnost določene stroke, je smiselno v zadevno razpravo pritegniti teorijo znaka. Semantična dvojnost označeno : označujoče velja tudi za terminologijo; smiselno pa je poudariti še tretji vidik, ki zadeva komuniciranje. O tem je obširno razpravljal Rudi Keller v svoji knjigi On Language Change (Keller 1994: 13-14). Ta povezovalni sociolingvistični vidik vzpostavlja dejaven odnos med obema enotama, ki zajema vse vrste pomenskega prelivanja, širjenje in oženje pomenov ter nastajanje novih pomenov. Keller sicer govori o splošnem jeziku, a prav tako upošteva tudi terminološko vedo, v kateri termini vstopajo v komunikacijske procese med drugim tudi glede na stopnjo določenega znanja različno ozaveščenih naslovnikov. 3 Tu ne gre samo za terminologizacijo in determinologizacijo, ampak tudi za terminološki dogovor, ki se še posebej oblikuje s komunikacijo.

1.2 Predmet določene vede se opredeljuje kot strokovno področje z določenimi posebnostmi. Z jezikovnega stališča vse to opisuje terminologija oziroma terminološka veda. Odgovor, kaj proučuje terminološka veda in kaj je terminologija, najdemo v novejši jezikoslovni literaturi. V terminološkem priročniku Špele Vintar z naslovom Terminologija piše: »Terminološka veda se ukvarja s termini kot poimenovanji za specializirane pojme določenega strokovnega področja. [...] Inventar jezikovnih poimenovanj pojmov neke stroke imenujemo terminologija, na primer geološka, medicinska, planinska terminologija.« (Vintar 2008: 18) Starejša literatura, katere predstavnik prav tako poudarja specifičnost izrazja, dodaja še konvencijo. Jože Toporišič v Enciklopediji slovenskega jezika ob iztočnici izrazje

2 Ker izraz terminologija zajema dva pomena, proučevanje strokovnega izrazja in izrazje samo, je za določnejšo pomensko osvetlitev smiselno uporabljati besedno zvezo terminološka leksika, ki jo navaja tudi Ada Vidovič Muha (2000: 116).

3 Mojca Žagar Karer (2011: 133-134) govori o sporazumevanju v strokovnih jezikih, pri čemer so tvorci zmeraj strokovnjaki, naslovnike pa zameji v tri skupine: strokovnjake, polstrokovnjake in nestrokovnjake. 
tako pravi: »Besede in besedne zveze, ki se $\mathrm{v}$ strokah dogovorno rabijo kot poimenovanja stvari in pojavov ter njihovih lastnosti, npr. zdravstveno, slovnično, politično, tehniško izrazje« (Toporišič 1992: 69). Izraz terminologija je podrejen in kot prednostni termin je navedeno izrazje. Nadalje Toporišič omenja, kar je že sam v obdelavi tega izraza uresničil, »pogoste dvojnice tipa domače - prevzeto, domače - t. i. mednarodno, npr. vratar - golman, zdravstvo - medicina«.

1.3 V zgornjih definicijah je v zvezi z opredeljevanjem terminologije poudarjen izraz stroka. Terminologija je s stališča besedja zbirka izrazov določene stroke. Če se ozremo na Slovar slovenskega knjižnega jezika (SSKJ2), ima izraz stroka naslednjo razlago: 'navadno s prilastkom posamezna gospodarska dejavnost, znanstvena panoga'. Izraz stroka zajema dve temeljni smeri človeške ustvarjalnosti, gospodarstvo in znanost. V sodobni terminološki literaturi pa najdemo o opredeljevanju področij človeške dejavnosti kot stroke omejitve. Razberemo jih lahko iz obravnave izraza strokovni jezik: »V slovenščini nam dela težave že izraz strokovni jezik, ki ga razumemo kot jezik stroke, se pravi jezik neke uveljavljene, posebno znanje zahtevajoče človeške dejavnosti. ${ }^{4}$ Po tej razmeroma široki definiciji stroke bi mednje sicer lahko šteli tudi športne in druge prostočasne dejavnosti, še vedno pa bi težko našli ljudi, ki bi govorili o stroki balinanja ali likanja.« (Vintar 2008: 14) Mojca Žagar Karer opozarja na nedorečenost oziroma ozkost merila specializiranosti izrazja: »Ko govorimo o strokovnem jeziku, se pojavi tudi vprašanje, kaj vse vključuje pojem stroka. Pri uveljavljenih znanstvenih področjih [...] načeloma ni težav, problem se lahko pojavi pri splošno populariziranih področjih, kot je šport, $\mathbf{5}$ ali pri vsakdanjih dejavnostih, saj je večina vsakdanjih dejavnosti do neke mere specializirana.« (Žagar Karer 2011: 127)

1.3.1 Pri iskanju meril za določitev strok s terminografskega stališča je pomembno poudariti, da so stroke različne. V strokovni literaturi je to pogosto omenjeno. Mojca Žagar Karer omenja, »da so terminološki sistemi bolj ali manj trdni in da so med različnimi vedami velike razlike«, in nadaljuje $\mathrm{z}$ delitvijo ved in njihovih terminov v dve skupini, v naravoslovne in tehniške vede ter humanistične vede. Za prvo so značilni »t. i. preskriptivni termini«, za drugo pa »t. i. psevdopreskriptivni termini«, pri čemer se psevdopreskriptivni termini razlikujejo od preskriptivnih po tem, da pogosto niso enopomenski, ustaljeni, gospodarni, neodvisni od besedila, zato jih je težje normirati: »Povezava med pojmom, terminom in definicijo je veliko bolj ohlapna kot pri preskriptivnih terminih « (Žagar Karer 2011: 35). Navedek napravi ločnico med vedami s tem, da terminom na humanističnem področju jemlje stopnjo, intenziteto predpisovalnosti. Razmislek o tem, kakšne

$4 \quad$ Tu ima citat tole opombo: »Po SSKJ celo le gospodarska dejavnost ali znanstvena panoga.«

5 Tu ima citat opombo, ki bo v nadaljevanju podrobneje razčlenjena: »V določenem institucionalnem okviru je šport seveda stroka (tudi v smislu znanstvene vede, saj ima svoj predmet in metode raziskovanja), po drugi strani pa bi recimo ukvarjanje z rekreativnim tekom težko označili za strokovno dejavnost.« 
možnosti pri tem nastopajo, vključuje rahljanje denotativnega pomena z večjo odprtostjo h konotacijam, kar privede do determinologizacije, na ravni naslovnika rečeno, da obstaja večja možnost, »da spoznavni subjekt (človek) po lastni presoji modificira spoznavni objekt« (Vidovič Muha 2000: 97).

2 Splošnejši uvod k obravnavani temi se zdaj nagiba k ponazarjanju. Merila, ki naj bi veljala za stroke, bodo v izhodišču obdelana na splošno, ne glede na predmet strok, konkretizirala pa se bodo ob stroki, ki ima poleg krovnih antropoloških karakteristik relevantne etnološke značilnosti, ob klekljarstvu. Vprašanje, ali to stroko lahko jemljemo kot vzorčno za antropološke vede, puščamo ob strani. Ker gre za terminologijo, izbiro utemeljujemo s tem, da je po besedah recenzenta MKS6 klekljarstvo prva od rokodelskih strok (tudi te odražajo način življenja in potemtakem spadajo v etnologijo), ki je terminološko obdelana.

2.1 Opredelitev MKS s stališča splošne teorije o terminoloških slovarjih ni enoznačna. Njegova makro- in mikrostruktura se v konceptu razlikuje od standardnih terminoloških slovarjev. Terminološka literatura namreč loči med strokovnimi slovarji na eni in terminološkimi slovarji na drugi strani (Košmrlj-Levačič 2007: 584). Strokovni slovarji »izkazujejo jezik stroke širše in ne le z vidika terminologije«, v terminoloških slovarjih pa »so kot iztočnice prikazani le terminologizirani leksemi, torej le termini«. V njih »med iztočnicami prevladujejo samostalniki in samostalniške besedne zveze, medtem ko najdemo v strokovnih slovarjih razen samostalnikov tudi pridevnike, glagole, prislove, redkeje tudi druge besednovrstne iztočnice« (Košmrlj-Levačič 2007: 584). Košmrlj-Levačičeva poudarja tudi zajetost besedne družine: »Oba tipa slovarjev se ločita tudi po tem, da so v strokovnem slovarju pogosto upoštevani skoraj vsi členi besedne družine, v terminološkem pa je izbor omejen le na člene, ki so pomembni z vidika pojmovnega sistema stroke« (Košmrlj-Levačič 2007: 584).

2.1.1 Navedenim postavkam bi dodali še naslednje, ki se izkazujejo v MKS. Strokovni slovarji se od terminoloških razlikujejo po zajetosti relevantne strokovne literature. Ciljnega gradiva ne zajamejo v najširšem obsegu, ampak izberejo tisto, ki je za določeno stroko temeljno, ob strani pa puščajo drugo, ki sicer prispeva k celoviti zajetosti, ni pa v stroki sami opredeljeno kot merodajno in služi za preverjanje prvega. MKS se je omejil na termine enega avtorja, uporabljene v strokovnem in leposlovnem korpusu, ki se nanaša na stroko. MKS namreč črpa termine iz leposlovnih del7 Tončke

$6 \quad$ MKS je recenziral prof. dr. Janez Bogataj.

7 Navajamo jih po časovnem zaporedju: Pravljice za Ajčko Bajčko in mamico, Celje: Mohorjeva družba, 1995; Podobe iz čipkaste preje, Ljubljana: Mladinska knjiga, 1996; Lučka na klekljarskih počitnicah, Celje: Mohorjeva družba, 2004; Pravljica o klekljarici Polonci: pišem, klekljam, Ljubljana: Pegaz International, 2006 (Knjižnica Žirovskega občasnika 10); Kaj je povedala babica: pravljica z zimskega okna, Žirovski občasnik: zbornik za vsa vprašanja na Žirovskem 31 (2010), št. 40, 154-155. 
Stanonik, ki je v letih 1995-2013 v petih delih zlasti z etnološkega stališča opisovala življenje klekljaric v Žirovski kotlini. Izrazje pa je nabrano tudi v strokovnem dodatku leksikonskega tipa $\mathrm{k}$ delu Lučka na klekljarskih počitnicah, ki klekljarske izraze iz osrednjega dela dopolnjuje s termini, ki jih v leposlovnem delu ni. Ker izbor terminov sloni na enem avtorju, se to leksikografsko delo po najbolj natančnih merilih opredeljuje kot avtorski strokovni slovar. ${ }^{8}$ Ob takem izboru terminov se pojavi zadržek, da omejitev na enega avtorja potencialno ne zajame vseh terminov določene stroke, ki pa ga je treba izločiti z objektivnimi ${ }^{9}$ in subjektivnimi merili.10

2.1.2 Kot je bilo omenjeno, se strokovni in terminološki slovarji razlikujejo v načelih o zajetosti iztočnic. Strokovni slovarji izhajajo iz besedilnega pristopa h gradivu določene stroke, terminološki pa iz pojmovnega sistema stroke, ki se izkazuje s termini. Besedilni pristop pritegne v slovar vse lekseme, ki se pojavljajo v določeni stroki, čeprav niso termini. Tako v MKS najdemo ženske in moške oblike za delujočo osebo, dovršne in nedovršne glagole iz istega korena, variantne besedne zveze in pisne dvojnice. MKS je kot iztočnice (zajetih je 407) sprejel tudi izraze, ki kažejo odnos avtorice Tončke Stanonik do klekljanja, to so subjektivno oblikovane metafore. Na primer: ovčice, paličice, potresavati s kleklji. Ti izrazi niso termini, a izhajajoč iz avtorskega koncepta slovarja dopolnjujejo prejšnjo ustaljeno klekljarsko leksiko.

2.1.3 Tej značilnosti avtorskega slovarja se pridružuje še druga, ki še poglablja osebno noto, ponazarja pa se z navajanjem citatov ${ }^{11}$ iz avtoričinih klekljarskih del ob posameznih klekljarskih izrazih. K sami razlagi termina citati prispevajo z enciklopedičnimi dodatki, kar naj ne bi bilo vsebovano $\mathrm{v}$ samih definicijah $\mathrm{v}$ terminoloških slovarjih, a je z njimi mogoče ponazarjati skladenjske možnosti. Namen MKS je bil torej predstaviti predvsem avtorsko specifiko izrazja z določenega etnološkega področja.

2.2 Možnost, da se razloček med strokovnimi in terminološkimi slovarji izrazi že v najbolj opaznem znamenju slovarske makrostrukture, daje tudi naslov. Pridevnik

8 Besedna zveza avtorski slovar se v pričujočem članku rabi v pomenu, kot ga navaja SSKJ; označena je kot lingvistični termin z razlago: 'avtorski slovar, ki vsebuje besede določenega avtorja'. Poleg tega pomena se v zadnjem času ta zveza uporablja tudi v pomenu 'slovar, ki ga sestavi en avtor', krajše bi bilo enoavtorski slovar, nasproti tistim, ki jih izdela komisija oziroma več avtorjev, kar bi bil večavtorski slovar. Prim. Fajfar-Žagar Karer 2013: 118: „V analizo časovne zaznamovanosti je bilo vključenih 35 slovarjev. 17 je avtorskih [...] Večavtorski slovarji (skupno 18 slovarjev) so [...] « Seštevek obeh skupin slovarjev da izhodiščno vsoto. Če pritegnemo tako pojmovanje avtorskih slovarjev, je MKS avtorski slovar tudi glede na enega avtorja.

9 Objektivno merilo bi vključevalo selektivno vzporejanje z morebitnimi obstoječimi geslovniki $\mathrm{v}$ določeni stroki.

10 V MKS je bila celovitost terminov preverjena s praktičnim znanjem klekljanja avtorice.

11 Citiranost izhaja že iz SSKJ2. Opredeljena je tako: „Citati se rabijo za ponazarjanje posebne (narečne ali individualne) rabe.« 
terminološki v naslovu ohranja relevantno znamenje pojmovnega sistema stroke. Opustitev tega pridevnika v naslovu pa nakazuje širšo zajetost izrazja stroke; pogosto je potem slovar identificiran z uslovarjenim jezikom. Tako imajo slovarji, ki so bili izdelani v Sekciji za terminološke slovarje Inštituta za slovenski jezik Frana Ramovša ZRC SAZU, naslove Botanični terminološki slovar, Geografski terminološki slovar, Geološki terminološki slovar na eni strani, na drugi pa Slovenski smučarski slovar, Slovenski tehniški slovar.12

3 Delni odmik od zastavljene povezovalne niti članka s prikazom koncepta MKS bo pojasnjen $\mathrm{v}$ nadaljevanju in bo smiselno povezan $\mathrm{s}$ pojmovanjem terminov $\mathrm{v}$ humanističnih vedah in z merili, opredeljujočimi stroke. Opazno je, da so bila nekatera od njih nakazana že v obstoječi terminološki literaturi.

3.1 Predmet stroke je najbolj relevantno sinhrono znamenje stroke, ki se odraža $\mathrm{v}$ njenem pojmovnem sistemu in je posredovano $\mathrm{z}$ izrazjem. V terminološki literaturi je to merilo v zvezi s športom omenjeno hkrati z drugim merilom, metodologijo: »V določenem institucionalnem okviru je šport seveda stroka (tudi v smislu znanstvene vede, saj ima svoj predmet in metode raziskovanja) [poudarila L. B.] «13 (Žagar Karer 2011: 127). V citatu je poleg teh dveh meril omenjeno tudi merilo izobraževanja, dostopa do znanja, kar bo obravnavano v nadaljevanju.

3.2 S predmetom stroke je povezana metodologija, ustaljeni sistematični postopki pri raziskovanju predmeta stroke. Metode strok so pri antropoloških in humanističnih strokah drugačne kot pri naravoslovnih in tehniških vedah. Pri humanističnih so v ospredju deskriptivne in primerjalne metode, ki vključujejo avdiovizualne vidike, pri naravoslovnih in tehniških pa je uveljavljena eksperimentalna metoda. Razlika je tudi v merljivosti rezultatov, ki je v tehniških in naravoslovnih vedah bolj v ospredju. Klekljarstvo kot ena od antropoloških strok se naslanja zlasti na deskriptivne razčlembe.

3.3 Stroke svoj predmet javno obelodanijo z izraznimi sredstvi, zlasti z jezikovnimi. Gre za literaturo o stroki, ki jo obravnavamo kot celoto strokovnih in znanstvenih del, v katerih je uzaveščeno znanje, na katero je naravnano človekovo delovanje. Navezava na klekljarstvo tu pokaže bogato klekljarsko bero. Kot vrhunec

12 Zavedajoč se te dvojnosti, je bil prvotno tako naslovljen tudi Čebelarski terminološki slovar, a je bil v korekturah pridevnik slovenski zamenjan s pridevnikom terminološki.

13 Nadaljevanje citata, ki je naveden v opombi, vključuje pomisleke o trditvi: »[...] po drugi strani pa bi recimo ukvarjanje $\mathrm{z}$ rekreativnim tekom težko označili za strokovno dejavnost« (Žagar Karer 2011: 127). Kdaj je neko ukvarjanje z nečim, kar sicer izhaja iz predmeta stroke, nepoklicno, puščamo tokrat ob strani. 
strokovne klekljarske literature omenimo monografijo Idrijska čipka - z nitjo pisana zgodovina (2013) in njeno angleško verzijo, v kateri je s terminografskega stališča med drugim tudi bogat nabor klekljarskih terminov.

3.4 S prejšnjim merilom je povezana institucionalizirana možnost izobraževanja, rezultat česar je prehajanje znanja med generacijami in določeno strokovno védenje. Špela Vintar ga omenja z izrazom »znanje«: »strokovni jezik [...] razumemo kot jezik stroke, se pravi jezik neke uveljavljene, posebno znanje [poudarila L. B.] zahtevajoče človeške dejavnosti« (Vintar 2008: 14). Znanje se pridobi $\mathrm{v}$ izobraževalnem procesu. To merilo vsebuje že zgoraj navedeni citat iz dela Mojce Žagar Karer (2011: 127): »V določenem institucionalnem okviru [poudarila L. B.] je šport seveda stroka [...].«14 Z izrazom »institucionalni okvir« se razume javna in organizirana skupnost ljudi, ki opravlja določeno izobraževalno dejavnost.

3.4.1 Javno organizirano pridobivanje znanja in vsesplošen dostop do njega ne glede na starost populacije izhaja iz potreb skupnosti. Določena stroka se ne more uveljavljati, če znanje o njej ne prehaja med ljudi. Glede na to, da je pridobivanje znanja največkrat vezano na mladino, je izobraževanje temelj, ki zagotavlja sprejemanje in dolgotrajno pronicanje terminološke leksike v vse pore družbenega življenja. Z mladimi generacijami se določeno izrazje širi in uveljavlja, pri čemer je še posebej poudarjena raba $\mathrm{v}$ medijih.

3.4.2 Na področju izobraževanja ima klekljarstvo dolgo tradicijo. Prva klekljarska šola je bila v Ljubljani ustanovljena leta 1763, v Idriji pa leta 1876. Klekljarske šole delujejo danes v Idriji, Žireh in Železnikih, klekljarski tečaji pa so organizirani po raznih krajih Slovenije.

3.5 Posebno merilo za opredeljevanje posameznih strok je standardizacija izrazja posameznih strok. Standardizacija pomeni enoumno določitev prepoznavnosti izdelka v vrsti sebi enakih, povezanih z določeno stroko. Mojca Žagar Karer večkrat omenja različno stopnjo standardizacije, pri čemer kot poseben člen v tem postopku nastopa terminološki dogovor: »Pri področjih, ki so bolj [poudarila L. B.] standardizirana [...], terminološki dogovor posredno nastaja tudi pri procesu standardizacije različnih proizvodov, procesov, storitev .... (Žagar Karer 2011: 18). Pri tem merilu se tehta tudi uresničevanje terminološkega dogovora: »Za nekatere stroke je standardizacija pomembnejša kot za druge - težave $\mathrm{z}$ natančnim sporazumevanjem imajo lahko usodne posledice denimo v letalskem prometu, pri električnih napeljavah itd." (Žagar Karer 2011: 18-19).

14 Prim. opombo 13 o relativizaciji trditve, ki se tu nanaša na v citatu poudarjeno besedno zvezo. 
3.5.1 Kako pa je s standardizacijo v antropoloških vedah, ki jih tu ponazarja klekljarstvo? Novejši čas je prinesel spremembe tudi na tem področju. Za pridobitev certifikata idrijska čipka je natančno navedeno, kako mora biti sklekljana. Občinski svet občine Idrija je leta 1999 sprejel Pravilnik o označbi porekla blaga z imenom idrijska čipka, v katerem je razdelek Definicija. Idrijska čipka je definirana tako: »Ročno klekljan izdelek, ki se je izoblikoval v daljšem časovnem obdobju na območju, idrijske čipke'15 in za katerega veljajo določene tehnične in tehnološke značilnosti« (Uradni list 1999). ${ }^{16}$ Čipke presojajo strokovno kvalificirane klekljarice. To pomeni, da se stroke v tem izenačujejo. Termin idrijska čipka lahko obravnavamo kot standardizirani termin.

3.6 Stroke po svoji osnovni dejavnosti niso enovite, ampak se pogosto notranje členijo v posamezne panoge. Široka krovna povezanost jim daje skupno jedro, ki se konkretizira $\mathrm{v}$ avtonomnih in od skupnega jedra ločenih vejah. Klekljarstvo se deli v posamezne veje, z bolj določno besedo imenovane tehnike. Tu omenimo samo ozki in široki ris. Že omenjena monografija o idrijski čipki pa ima za tehnike klekljanja navedenih kar 57 poimenovanj. ${ }^{\mathbf{1 7}}$ Naravoslovne in tehniške stroke se prav tako delijo v posamezne panoge, na primer kemija v organsko in anorgansko kemijo, elektrotehnika $v$ telekomunikacije in energetiko.

3.7 Interdisciplinarnost strok je merilo, ki ga je mogoče utemeljevati z njihovo premajhno samozadostnostjo za raziskovanje neznanih ali premalo znanih področij predmeta določene stroke. Trditev je mogoče navezati na pojmovni sistem, ki je konkretiziran s terminološko leksiko. Izrazni sistem vsake stroke namreč oblikujejo termini, ki so v stroki polno umeščeni, zato so zanjo bistveni, nosilni. Ti relevantni termini imajo v pojmovnem sistemu stroke svoje nepogrešljivo mesto, z njimi je označen predmet stroke. Strokovno izrazje posameznih strok pa zajemajo tudi izrazi, ki so v določeni stroki le delno umeščeni, v njej le gostujejo $\mathbf{1 8}$ in prispevajo k interdisciplinarnosti vede oziroma $\mathrm{k}$ širjenju in poglabljanju predmeta vede. ${ }^{19}$ Pogosto

$15 \mathrm{~V}$ definiciji je uporabljen termin, ki se pojasnjuje, kar bi bilo s terminografskega stališča primerneje zamenjati s konkretno geografsko navedbo, kaj je v stroki opredeljeno kot dežela oziroma območje idrijske čipke.

16 Pravilnik je bil dopolnjen v Uradnem listu dne 7. 7. $2000 \mathrm{z}$ objavo o konkretnih spremembah.

17 Ob tolikšnem številu tehnik je morda upravičen dvom o pravilni uporabi izraza tehnika, a razpravljanje o tem ne spada $\mathrm{v}$ kontekst članka.

18 Izraziz te besedne družine (gostovanje) uporablja tudi Ada Vidovič Muha, ko opisuje stilno učinkovanje leksike zunaj njene primarne rabe: »Stilno učinkovanje leksike s socialno- ali funkcijskozvrstno prepoznavnimi prvinami pa je vezano na njeno medzvrstno rabo, ali drugače: gostovanje katerekoli na določen sporočanjski (komunikacijski) položaj ali področje vezane leksike v njej nelastnem sporočanjskem okolju ima moč stilema. V tem smislu lahko učinkuje tudi raba (znanstvenega) termina zunaj knjižnojezikovnega področja, seveda pa je zlasti opazna tovrstna stilistika na ravni knjižnega jezika, se pravi raba npr. narečnega, slengovskega ipd. izrazja.« (Vidovič Muha 2000: 98)

19 Za čebelarsko stroko je $\mathrm{v}$ literaturi navedenih deset interdisciplinarnih strok (veterina, botanika, biologija, zoologija, kemija, medicina, kulinarika, genetika, ekologija, etnologija). Prim. Bokal 2009: 106-113. 
se teoretično in praktično izpopolnjevanje vedenja o določeni stroki odraža prav v delno umeščenih terminih. S stališča terminografske obdelave se pri njih pogosto pojavlja vprašanje o vključitvi oziroma nevključitvi v slovar.

3.7.1 Če se osredotočimo na klekljarstvo, so relevantni termini klekelj s celotno besedno družino, vzorčna predloga, sukanec, slepi ris, široki ris, klekljarska blazina. Tovrstno relativno samostojnost jedrnega klekljarskega izrazja $\mathrm{v}$ zadnjih desetletjih širijo izrazi iz novejše klekljarske leksike - zaščiteno geografsko poreklo idrijske čipke, ${ }^{20}$ unikatna čipka, ${ }^{21}$ avtorska čipka -, ki segajo na pravno področje, mednarodna barvna skala 22 pa na operativni vidik izdelave čipk.

3.8 Da je neka dejavnost opredeljena kot stroka, mora imeti možnosti razvoja. Ostajanje na določeni stopnji prej ali slej vodi v nazadovanje, ki se konča v zamrtju. Vključujoč merilo o interdisciplinarnosti, je rodovitno znamenje razvoja stroke prav številčno večanje delno umeščenih terminov v pojmovnem sistemu stroke.

3.8.1 Klekljarstvo se ne širi samo v horizontalni smeri, ki bi ga ponazarjala slovenska regijska območja in bo natančnejše pojasnjeno v nadaljevanju, veča se tudi njegova notranja diferenciacija. Raznovrstnost figuralnih, živalskih in rastlinskih motivov vključuje nove prijeme, dinamika vpletanja $v$ tekstilne izdelke pa išče vedno nove možnosti. Tu bi omenili samo neke vrste klekljano grafiko Urha Sobočana, ki klekljarsko znanje prenaša $\mathrm{v}$ likovno oblikovane motive.

3.9 Glede na populacijo in starostni razpon dejavnosti naj stroke ne bi imele zadržkov. Populacijsko merilo vključuje moške in ženske vseh starosti, kolikor jih pač ne ovirajo osebne lastnosti. Kljub temu da je klekljanje vezano bolj na ženski svet, so se z njim ukvarjali tudi moški. Predvsem pa je pomembno, da so to znanje pridobivali mladi. Poznamo družine, v katerih klekljajo člani več generacij, tako ženske kot moški.

3.10 Naslednja postavka se dotika vsakokratne praktične vraščenosti določene stroke v skupnost in prepoznavnost, kjer živi. Tu pridejo do izraza oblike javnega predstavljanja in populariziranja dosežkov na prireditvah (moderen izraz v zvezi s tem je promocija), ki se konkretizirajo $\mathrm{v}$ razstavah, raziskovalnih taborih, festivalih, seminarjih in v medosebnem primerjanju kvalitete, vezane na konkretne predmete ali dejavnost kot tako, kar se pokaže na tekmovanjih.

20 Termin ima $\mathrm{v}$ MKS naslednjo definicijo: zaščiteno geografsko poreklo idrijske čipke [...] $\mathrm{s}$ pravnim predpisom zavarovane značilnosti idrijske čipke glede na določeno geografsko območje.

21 Termin ima v MKS definicijo: unikatna čipka [...] čipka, ki je enkraten, izviren izdelek določene avtorice.

22 MKS: mednarodna barvna skala [...] z barvami dogovorjen način razpoznavanja klekljarskih prvin, tehnik na klekljarskem vzorcu. 
3.10.1 Klekljarstvo v zadnjem desetletju tako rekoč nenehno doživlja javne potrditve v vseh zgoraj omenjenih oblikah. Omenimo Festival idrijske čipke, še posebej pa so popularni t. i. dnevi, na primer Slovenski klekljarski dnevi v Žireh in Čipkarski dnevi v Železnikih, povezani z razstavami, etnološkimi, kulturnimi, otroškimi in športnimi dogodki, trajajočimi več dni.

3.10.2 Tudi naravoslovne in tehniške stroke pri tem nimajo omejitev. Javno predstavljanje je pri njih sicer manj vezano na zabavne in kratkotrajne informativne objektivizirane oblike, kot so razstave, vendar se zadevne stroke dokazujejo z zavzetimi oblikami zlasti javnih predavanj, seminarjev in mladinskih tekmovanj.

3.11 Geografska razširjenost stroke je merilo, ki ga določa uveljavitev dejavnosti v širšem prostoru. Stroka, vezana na ozko območje, prej ali slej ponikne in postane le predmet etnoloških obdelav in prikazov. S tega stališča je pomembna tudi izmenjava strokovnih dognanj ter medregijsko ali mednarodno povezovanje nosilcev stroke.

3.11.1 Klekljanju s tega stališča ne gre oporekati. Ne samo v Sloveniji, tudi v Evropi in še širše v svetu je uveljavljeno kot umetnost bele niti, ki ima svoje strokovno združenje 23 in redno izhajajočo revijo. ${ }^{24}$ Povezovalni člen pri ustvarjalnem praktičnem dejstvu je že omenjena mednarodna barvna skala, ki predpisuje način, po katerem je mogoče izdelovati čipke ne glede na izvorno narodno pripadnost. Dokaz geografske razširjenosti je tudi svetovni kongres klekljaric oziroma čipkaric vsaki dve leti. Junija 2016 bo svetovni čipkarski kongres v Sloveniji, organizira pa ga za to priložnost ustanovljena Ustanova OIDFA kongres Slovenija 2016.

3.12 Če k sinhronim merilom pritegnemo še diahroni vidik, je tradicija tisto, kar daje stroki veljavo glede na časovno trajanje v stvarnosti. Ada Vidovič Muha tradicijo jemlje kot »dokaz starosti oz. uveljavljenosti stroke« (Vidovič Muha 2000: 119) in jo navezuje na terminološko ustaljenost. To merilo je neposredno povezano $\mathrm{s}$ socialno dimenzijo nosilcev stroke. Prenašanje vedenjskih nastopov, vezanih na skupnost, iz roda v rod se je poenotilo v skupnih vzorcih vedênja, ki s ponavljanjem dobijo ustaljeno obliko. Pogosto se izrazijo v navadah in običajih.

3.12.1 Klekljarstvo je zaznamovano s tradicijo. Najprej je zaživelo na gradovih, od tam pa se je razširilo v premoženjsko šibkejše sloje in se uveljavilo kot domača obrt, ki jo je napajala za življenje pomembna silnica - klekljarstvo je bilo dodaten vir zaslužka. Pri tem ne gre zanemariti tudi skupnostnega motiva, da je bilo klekljanje vedno družabna dejavnost. Socialna psihologija bi mu v obravnavi te plati

23 Združenje se imenuje OIDFA (L'Organisation Internationale de la Dentelle au Fuseau et à l'Aiguille) in je bilo ustanovljeno leta 1982.

24 Revija ima naslov Bulletin OIDFA in izhaja četrtletno. 
doživljanja dala veliko vrednost. Klekljarice so hodile na obisk ena k drugi, hodile so v vas, na prejo.

3.12.2 Naravoslovne in tehniške stroke tradicije kot take ne vključujejo. Njihova temeljna obravnava ni povezana s tisto silnico človeške dejavnosti, ki bi jo usmerjala $\mathrm{v}$ take družbene odnose in komunikacijske stike, na podlagi katerih bi nastali določeni ustaljeni rituali, navade in običaji. Primeri za to so matematika, kemija in elektrotehnika.

3.13 Strokovno področje klekljarstva bogatega znanja nima spravljenega le $\mathrm{z}$ objektiviziranimi deli, zajetimi v literaturi. Njihova nadgradnja so tudi subjektivizirana besedila, ki z metaforičnimi klekljarskimi izrazi dopolnjujejo strogo strokovno enopomensko razsežnost terminološkega razumevanja besedil. Kot je bilo omenjeno pri MKS, so v njem med iztočnicami tudi metaforični izrazi, ki so konotativni ustreznik klekljarskim terminom: klekljarska bera, klekljarska abeceda in klekljarska poštevanka. S terminološkega stališča taki klekljarski izrazi nakazujejo ohlapnost ali odprtost terminov v humanističnih in antropoloških strokah, o katerih je bilo govora na začetku sestavka $v$ zvezi s psevdopreskriptivnostjo terminov. Predpostavka, da ti termini lažje vzpostavljajo konotativne pomene, bi bila privlačno izhodišče za poglobljeno nadaljnjo raziskavo. Tu pride do veljave ustvarjalna moč posameznika, ki se kaže v asociativno bogatih ubeseditvah. Razmerje med pojmom in terminom se tako rahlja in $\mathrm{s}$ tem se potrjuje dognanje, da $\mathrm{v}$ družboslovnih in humanističnih strokah »razmerje med terminom in pojmom ni jasno in nedvoumno« (Žagar Karer 2011: 147). ${ }^{25}$

4 Zunanja merila, opredeljujoča stroko, naj dopolnijo notranjejezikovne posebnosti. Že v uvodnem delu sestavka je bilo omenjeno, da je bistveno znamenje samostojnosti stroke izrazje. Pojmi sedejo v pojmovni sistem stroke, kako se umestijo, katera od jezikovnih ravnin se pri tem odrazi, kako se pojmovni sistem kot celota izkazuje in ali sodeluje tudi slovnica, pa so notranjejezikovna vprašanja, ki še čakajo na odgovor.

4.1 Ob tem predpostavljamo, da se terminološka leksika ne izkazuje samo na pomenski jezikovni ravnini. Posebnosti terminov določene stroke lahko segajo celo $\mathrm{v}$ slovnico in tudi na druge jezikovne ravnine.

4.2 Pregled po terminološki klekljarski leksiki se ustavi pri besedotvorju, natančneje pri tvorjenkah, in to tistih, ki so glede na besedotvorno vrsto izpeljanke. Posebno področje klekljarske leksike namreč oblikujejo termini za poimenovanje čipk:

25 Mojca Žagar Karer omenja nejasnosti in potrebo po interpretaciji v pravnih besedilih. 
križčevke, zibke, rogljički, srčkovke, bunke, cvetke, cvetkove (izpridevniška tvorba samostalnikov je pogosta), gobice, krizanteme, metrovke, mizice, močeradovke, pajki, pajkove, potonike, ribice, slince, štručke, vejevke, žabice.

4.2.1 Njihova opazna slovnična lastnost se razkriva v slovnični kategoriji števila. Vsi izrazi so v množini, množinska raba je torej relevantno znamenje tistega dela klekljarskih terminov, ki poimenujejo čipke. Izvor take slovnične posebnosti določa oblika teh čipk. Posamezen klekljarski prtiček namreč sestavljajo ponavljajoče se oblike figur, katerih poimenovanja izvirajo iz splošnega botaničnega področja (cvetke), iz prepoznavnih oblik cvetov ali celotnih rastlin (krizanteme, potonike; gobice), iz poimenovanj živali s prepoznavnimi oblikami (močeradovke, žabice, ribice, pajki) ali celo iz poimenovanj vsakdanjih uporabnih predmetov (mizice, zibke). ${ }^{26}$ Klekljarski termini za poimenovanje posameznih čipk so torej množinski samostalniki. Kategorialna pomenska sestavina števnosti27 se pri množinskih samostalnikih veže z ločilnimi števniki. Tako je tudi pri teh klekljarskih terminih: enoje križčevke, dvoje križčevke itd.

4.2.2 Poleg te slovnične posebnosti imajo ti klekljarski termini še prepoznavno besedotvorno obliko. Ada Vidovič Muha tvorjenkam pripisuje možnost zapolnjevanja praznih mest v leksikalnem sistemu: »Tvorjenke so glede netvorjenke besede z najmanj enim morfemom več, njihova morfemska zgradba je torej zapletenejša, večja pomenska obremenitev pa zato pričakovana. Morfemi, ki se v tvorjenkah pojavljajo, so obrazilni, kar pomeni, da imajo za razliko od npr. slovničnih morfemov, ki samo prirejajo (iste) besede za različne skladenjske vloge, moč tvorjenja novih (besednih) leksemov, besed torej, da so skratka besedotvorni.«(Vidovič Muha 2000: 39) Klekljarski termini z omenjenega področja so manjšalnice. Manjšalnica je »[t]vorjenka, zlasti samostalniška, ki s priponskim obrazilom izraža manjšo mero značilnosti podstave« (Toporišič 1992: 100). Pojav manjšalnic v klekljarski terminološki leksiki se torej navezuje na pomanjšanje izraza v korenu termina, in sicer na nevtralno sestavino, in ne na ekspresivno, ki jo manjšalnice pogosto vsebujejo. Merilom za presojanje stroke se tako pridružujejo tudi notranjejezikovne posebnosti posameznih strok.

26 Zakaj so $\mathrm{k}$ temu pritegnjeni le leseni predmeti, je vprašanje, ki odpira področje materialne kulture in še ožje bivalne kulture določenega območja.

27 Kljub temu da posamezno čipko sestavlja množica posameznih figur, izraza samega ne moremo obravnavati z vidika podspola neštevnosti (najbližje bi mu bila oznaka »skupno«), ki je po Adi Vidovič opredeljen tako: »Med kategorialne pomenske sestavine sodi tudi števnost: kot je znano iz slovnic, je brez oznake števnosti (neštevna) snovnost - snovni samostalniki [...], pojmovni samostalniki [...] in kot kategorialna modifikacijska pomenska sestavina skupno, npr. vejevje, srnjad - obrazilna (besedotvorna modifikacija jedra tip veliko (srn) (srn)-jad« (Vidovič Muha 2000: 33). 
5 Zgoraj opisanih meril za določanje strok s terminografskega stališča ne moremo obravnavati ločeno - vsa so teoretično in praktično povezana med seboj v enovito celoto, ki jo stroka kot taka izraža.

6 Sestavek nima namena razpravljati o upravičenosti terminografske obdelave posameznih področij, osvetliti želi le možnosti za presojanje strokovne »senzibilnosti« posameznih ved, s prikazom meril, ki opredeljujejo stroko, pa skuša prikazati, kako tudi obrobne antropološke stroke pridobivajo terminografsko enakopravnost, postajajo s tega stališča zanimivejše in se terminologizirajo.

\section{LITERATURA}

Bokal 2009 = Ljudmila Bokal, Plasti čebelarskega izrazja, v: Naj medi!: ob 100-letnici ČD Grosuplje, ur. Jakob Müller, Grosuplje: Čebelarsko društvo, 2009, 106-113.

Fajfar - Žagar Karer 2013 = Tanja Fajfar - Mojca Žagar Karer, Časovna zaznamovanost v terminoloških slovarjih, v: Družbena funkcijskost jezika: vidiki, merila, opredelitve, ur. Andreja Žele, Ljubljana: Znanstvena založba Filozofske fakultete, 2013 (Obdobja 32), 117-123.

Jemec Tomazin $\mathbf{2 0 1 0}$ = Mateja Jemec Tomazin, Slovenska pravna terminologija: od začetkov $v 19$. stoletju do danes, Ljubljana: Založba ZRC, ZRC SAZU, 2010 (Lingua Slovenica 5).

Keller 1994 = Rudi Keller, On Language Change: the invisible hand in language, London: Routledge, 1994.

Košmrlj-Levačič $\mathbf{2 0 0 7}$ = Borislava Košmrlj-Levačič, O terminih z vidika terminografske prakse, v: Razvoj slovenskega strokovnega jezika, ur. Irena Orel, Ljubljana: Filozofska fakulteta, Oddelek za slovenistiko, Center za slovenščino kot drugi/tuji jezik, 2007 (Obdobja 24), 583-598.

Leskovec idr. 2012 = Ivana Leskovec idr., Idrijska čipka, z nitjo pisana zgodovina, Idrija: Mestni muzej, 2012.

MKS = Ljudmila Bokal, Mali klekljarski slovar iz žirovskih del Tončke Stanonik, Ljubljana: Založba ZRC, ZRC SAZU, 2013.

SSKJ2 = Slovar slovenskega knjižnega jezika: druga, dopolnjena in deloma prenovljena izdaja 1-2, Ljubljana: SAZU - ZRC SAZU, Inštitut za slovenski jezik Frana Ramovša (izd.) - Cankarjeva založba (zal.), 2014.

Toporišič 1992 = Jože Toporišič, Enciklopedija slovenskega jezika, Ljubljana: Cankarjeva založba, 1992 (Leksikoni Cankarjeve založbe, zbirka Sopotnik).

Toporišič $\mathbf{2 0 0 0}$ = Jože Toporišič, Slovenska slovnica, Maribor: Obzorja, 42000 (11976).

Uradni list 1999 = Uradni list Republike Slovenije, št. 67/1999 z dne 19. 8. 1999 〈http://www. uradni-list.si/1/content?id=26602 , dostop 3. 5. 2015.

Vidovič Muha $\mathbf{2 0 0 0}$ = Ada Vidovič Muha, Slovensko leksikalno pomenoslovje: govorica slovarja, Ljubljana: Znanstveni inštitut Filozofske fakultete, 2000 (Razprave Filozofske fakultete).

Vintar 2008 = Špela Vintar, Terminologija: terminološka veda in računalniško podprta terminografija, Ljubljana: Znanstvena založba Filozofske fakultete, 2008 (Prevodoslovje in uporabno jezikoslovje).

Žagar Karer 2011 = Mojca Žagar Karer, Terminologija med slovarjem in besedilom: analiza elektrotehniške terminologije, Ljubljana: Založba ZRC, ZRC SAZU, 2011 (Linguistica et philologica 26). 


\section{SUMMARY}

\section{A Profession as a Terminographic Point of Departure (Lace-Making Terminology)}

Professions are most of all distinguished by the specific expressions that are connected with the profession's subject area and that point to the autonomy of a particular professional area. The subject area of a profession is its most relevant synchronic characteristic, which is expressed in its conceptual system and is transmitted through terminology. In addition to their subject area, which is one of the metalinguistic criteria for defining professions, professions are also defined by methodology, various degrees of terminological standardization, inclusion of knowledge in relevant literature, institutionalized opportunity for education, internal division into individual branches, interdisciplinarity, which may be justified by the self-sufficiency of professions being too small to research their unknown areas, the possibility of development, the criterion of including the entire population, the criterion of a particular profession's embeddedness in the community and its public recognition, and the geographical scope of the profession. These synchronic criteria are joined by the diachronic perspective, which is attested in tradition. Professions are also justified through their special internal linguistic features. These criteria are illustrated in the article with lace-making terminology. Its perceptible grammatical character is revealed in the grammatical category of number (plural) in expressions for lace and with a characteristic word-formational form (diminutives). This is attested by Mali klekljarski slovar iz žirovskih del Tončke Stanonik (Pocket Lace-Making Dictionary from the Žiri works of Tončka Stanonik, 2013) of Ljudmila Bokal, demonstrating that marginal anthropological areas are also of terminographic interest and are codified in terminology. 